\section{Stripes on a pterosaur wing}

SIR-D. Martill and D. Unwin in their recent Letter to Nature described a pterodactyl fossil in which details of the soft tissues of the wing membrane were preserved. Scanning electron microscopy revealed an epidermal layer on one surface of the specimen, with coarse ridges and finer furrows, below which was a spongy layer said to contain blood vessels. Martill and Unwin interpreted this 'stratum vasculosum', together with an underlying coarsely crystalline layer, as the dermis. Below that was a layer they described as striated muscle, which apparently formed the middle of the original membrane, but the authors did not explain why they thought this layer was muscle. It consisted of polygonal prisms with a maximum diameter of about $40 \mu \mathrm{m}$, on which Martill and Unwin said that "transverse striae and nuclei" were visible at high magnification. They did not illustrate these striae, or give any details. The features seen in the electron micrographs would presumably be annular ridges or grooves around the circumference of the prisms.

There are examples of fossils in which very fine details of the surface of soft tissues have been preserved, apparently by the deposition of a calcite 'mould' of the surface, before the tissues decayed ${ }^{2.3}$. This process preserves only surface relief, and it is unlikely that intracellular structures such as muscle striae (sarcomeres) could be preserved in this way. The sarcomeres of fresh striated muscles have a solid appearance under the light microscope, but are not accompanied by annular corrugations on the surface of the fibre. It is conceivable that the sarcolemma might be deformed into annular wrinkles in a strongly contracted muscle fibre, but striae formed in this way would not represent sarcomeres. For a surface mould to be formed that would show such features, the muscle fibres would in any case have to remain in tetanic contraction for some time after death, which seems unlikely. On the other hand, passive elastic fibres would contract when the animal died. Elastic fibres, if they were enclosed in a relatively inextensible sheath, might well exhibit a surface pattern like that reported by Martill and Unwin in their paper.

I reviewed evidence ${ }^{2}$ indicating that the ridges on the wing surfaces of certain pterosaur fossils are not stiffening fibres, as had been previously thought, but are wrinkles in the surface of a soft membrane, caused by the contraction of robust (but unseen) internal elastic fibres. These hypothetical elastic fibres would have to be orientated transversely to the wrinkles, not parallel to them as shown by Martill and Unwin in their Fig. 3c. Martill and Unwin's observations could be inter- preted as the first direct evidence for the existence of these fibres.

\section{J. PENNYCUICK}

Department of Biology,

University of Miami, PO Box 249118.

Coral Gables, Florida 33124, USA

MARTILL ET AL. REPLY-Pennycuick suggests that we may have misinterpreted the polygonal fibres in our exceptionally well-preserved pterosaur wing membrane from the Santana Formation (Lower

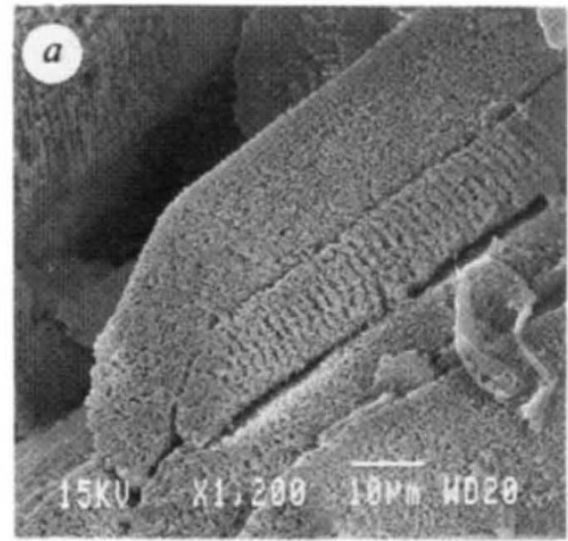

a. Striated muscle fibres from pterosaur wing membrane from the Santana Formation, Brazil. $b$, Oblique section through individual fibre demonstrating continuity of surface banding through body of fibre. We interpret the banding as fossil sarcomeres.

Cretaceous) of Brazil. We concluded that the fibres represent striated muscle replaced by cryptocrystalline calcium phosphate. Pennycuick believes that the fibres represent his hypothetical 'elastic' fibres $^{2}$, which he suggested as a possible mechanism for contraction of the flight membrane on the basis of impressions in fine-grained sediments. We here review our evidence for interpreting these fibres as striated muscle and report briefly on our new studies of this tissue.

The most common soft tissues found in the Santana Formation are striated muscle and gill lamellae of elopomorph fish ${ }^{4}$. Here, the muscle fibres are found in their original myomeres, and there is no doubt that they represent fossil striated muscle fibres. They even show sarcolemic membranes, cell nuclei, myoseptal membranes and sarcomeres ${ }^{5}$. Preservation is by replacement with calcium phosphate as demonstrated by powder $\mathrm{X}$ ray diffractometry. The fibres we found ${ }^{\prime}$ resemble very closely the muscle fibres found in the fish. Furthermore, pterosaur fibres display a regular banding seen on the surface.

Pennycuick suggests that striated muscle would not be preserved as a series of ridges on the surface of a fibre. Indeed in this respect he is correct. Our striated muscle fibres are not preserved as a series of ridges. Instead, they are preserved as a series of stacked 'disks' along the length of each fibre ( $a$ in the figure). We have carefully made a new section through the

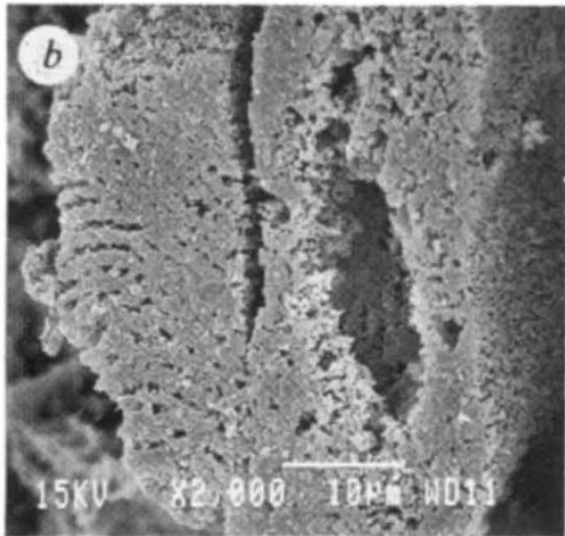

preserved muscle fibres such that several individual fibres have been cut obliquely, showing that the disks are present through the fibre, as would be expected if sarcomeres were preserved ( $b$ in the figure).

Pennycuick's surprise at the exceptional preservation of our material could be because the material he examined was represented by external moulds in finegrained micrite. This style of preservation can only reveal details of external surfaces, the resolution of which is governed by the grain size of the sediment host. Our material, on the other hand, is a replace-

ment, in three dimensions, by crystallites with an average length of 300 nannometres. The resolution achieved by this style of preservation allows the identification and accurate observation of threedimensional intracellular structures. We are confident that the fibres are those of striated muscle tissue.

But our new section shows some structures between the muscle fibres and the stratum spongiosum (labelled sparry calcite and kerogen in Fig. $3 a$ of ref. 1), as yet unidentified, that could be Pennycuick's hypothetical elastic fibres or Wellnhofer's stiffening rods ${ }^{6}$. In either case it appears that the pterosaur wing membrane is a highly complex organ, not just a piece of stiffened skin.

DAVID M. MARTILL PHILIP WILBY

Department of Earth Sciences.

Open University,

Milton Keynes MK7 6AA, UK DAVID M. UNWIN

Palaeontological Institute,

Academy of Sciences of USSR,

Moscow, USSR

1. Martill, D.M. \& Unwin, D.M. Nature 340, 138 (1989) . Pennycuick C.J. Biol Rev 63. 299-331 (1988)

Rietschel, S. in The Beginnings of Birds (eds Hecht, M.K Ostrom, J.H., Viohl, G. \& Wellnhofer, P.) 251-260 (Jura Museum, Willibaldsburg, 1985)

4. Martill, D.M. Palaeontology 31, 1-18 (1988).

5. Martill, D. M. Nature 346, 171 (1990).

Wellnhofer, P. Mitt. bayer. Staatssig. Palaeont. hist. Geol. 27, 175-186 (1987)

- Martill's data on fish, referred to above, are published on page 171. 